Japan. J. Med. Sci. Biol., 33, 155-165, 1980

\title{
AN APPLICATION OF FACTOR ANALYTICS ON ANTIGENIC DRIFT, AND CHROMATOGRAPHIC ANALYSIS ON INTRATYPIC VARIATION OF ENTEROVIRUS TYPE 70
}

\author{
HIRoYoshI KAWAMOTO \\ Department of Microbiology, Gifu Prefectural Institute of Public Health, \\ 6-3, Noishiki 4-chome, Gifu 500, Japan
}

(Received, October 8, 1979. Accepted, January 31, 1980)

\begin{abstract}
SUMMARY: An attempt was made to reveal the antigenic determinant site of enterovirus (EV) 70 by application of Harman's factor analytics. The normarized neutralization rate constant $(\mathrm{NK})$ values obtained by the kinetic-neutralization tests (NT) with 12 strains of EV70 isolated during the period from 1971 to 1976 were used in the principal factor analysis. From the analytic results, it was suggested that at least two antigenic determinant sites, composing to variable antigenic factor (VAF) and common one (CAF), might be closely related to the antigenic makeup. There were no significant differences in CAF score among the strains, and they were numerically classified into prototype-like and prime-like virus groups from the VAF scores. The drift appeared here could be explained as successive alteration of VAF scores.

Chromatographic analyses were carried out on intratypic variable and common particles with two virus strains, i.e. the prototype J670/71 and prime G-2/74. The intratypic variable and common particles were eluted in low and high ionic concentrations at neutral $\mathrm{pH}$, respectively. It was concluded that the virus populations of two strains were heterogenic in the proportion of variable to common virus particles.
\end{abstract}

\section{INTRODUCTION}

Intratypic variation of EV70 has been considered to be an antigenic drift successively occurring from prototype-like viruses to prime-like ones since its introduction into Japan in 1971. As a probable aspect, it was proposed that EV70 might be such a type of virus of antigenic heterogeneity in a previous report (Kawamoto, 1979). In facts, acute hemorrhagic conjunctivitis (AHC) caused by a prototype-like strain has rarely occurred in Japan since 1974 (Ishii, Nakazono and Sawada, 1977; Kawamoto, 1976, 1979). Such a heterogeneity is well known to exist widely among enteroviruses and to be an established character of a given population of virus particles (Abraham, 1967; Choppin and Eggers, 1962; Dömök and Simon, 1966; Gaudin et al., 1971; Margalith et al., 1968; Simon and Dömök, 1963). In the present study, at first, an attempt was made to reveal the antigenic determinant sites of EV70 by application of Harman's

川本尋義（岐皁県衛生研究所 岐阜市野一色 4-6-3) 
factor analytics (1967). This analytics was developed originally in psychology. In this report, the drift phenomenon of EV70 was analyzed by comparing the strains' factor scores assigned significances in respective antigenic characteristics. Secondly, the elution behavior in adsorption chromatography was analyzed to find the heterogeneity of EV70 among strains.

\section{MAterials AND Methods}

\section{Experiment 1: Numerical analytics of neutralization activities among EV70 strains}

Introduction into factor analytics: The 72 normarized neutralization rate constant $(\mathrm{NK})$ values calculated for serum-virus combinations of 12 isolates obtained during the period from 1971 to 1976 and six rabbit hyperimmune sera by a modification of McBride's neutralization kinetics (1959) were used as principal data introduced into factor analytics. The data have been reported in a previous report (Kawamoto, 1979). The NK value was useful as a summary measure showing either antigenic similarity or diversity. Although factor analytics applied here was developed originally as a numerical procedure for multivaliate analysis in psychology, it has often been applied to epidemiological studies from the public health aspect e.g. that by Nakamura et al. (1978). However, it has scarcely been applied to virological study. As a factor model in the present study, an experimental variable, i.e. NK values on antigen-antibody reactions, could be explained in one dimentional structure of elemental subvariables.

For example, the equation is as follows:

$$
z_{i j}=a_{j i} f_{i l}+a_{j 2} f_{i 2}+\cdots+a_{j m} f_{i m}+d_{j} u_{i j}
$$

where $a_{j m}$ is coefficient, so-called "factor loading", which related a variable factor with a common one, whereas $f_{i m}$ is a hypothetic common variable, socalled "factor score". It was defined that antigenic characteristics of each strain could be mathematically expressed as a factor score in varying proportional possession of individual antibody makeup which was designated in the place of different antigenic determinant sites on virus particles. Hence, their mathematical details will be after illustrated in basics of factor analytics.

Basics of factor analytics: As shown in Table I, the kinetic results are summarized as principal data matrix $X$. Correlation coefficients, calculated from possible combinations of columns in the matrix $X$, are summarized as correlation matrix $R$ shown in Table II. The matrix $R$ was used to calculate factor loading matrix $A$ explained by the following equation:

$$
\begin{aligned}
& R=A A^{\prime}+D^{2} \\
& R^{*}=A A^{\prime} \quad\left(R^{*}=R-D^{2}\right)
\end{aligned}
$$

where matrix $A^{\prime}$ is transposed matrix, and matrix $D$ of unknown factor is diagonal matrix composed of uniquness $\left(d_{j}{ }^{2}\right)$ as elements. That is to say, matrix $R$ can be approximated to a product $A A^{\prime}$, whereas data matrix $X$ can be stand- 
ardized by the following equation:

$$
Z=\left(X-1 m^{\prime}\right) \Sigma^{-1}
$$

where $m$ is vector composed of mean of each column in matrix $X$ as element, and $\sum^{-1}$ is diagonal matrix composed of standard diviation of each column in matrix $X$ as element. Accordingly, factor score matrix $F$ can be expressed by the following equation:

$$
Z=F A^{\prime}+U D
$$

where matrix $U D$ is product of factor loading and factor score of unknown factor. It can be neglected in this part, if it is small enough. Additionally, if original matrix $X$ is used, factor score matrix $F$ should be further arranged as the following equation:

$$
F=\left(X-1 m^{\prime}\right) \sum^{-1}\left(A^{\prime}\right)^{-1}
$$

where matrix $\left(\mathrm{A}^{\prime}\right)^{-1}$ is inverted matrix, and it is difined as weight coefficient matrix to be used to estimate factor score. Accordingly, distribution of factor score given here will naturally follow standardized distribution.

Practice of analytics: Factor analysis applied here was carried out according to the modification of original Harman's procedure reported by Shiba (1976).

\section{Experiment 2: Adsorption chromatography with hydroxyl apatite gel}

Viruses: Two seed viruses, selected from two antigenic subgroups, i.e. the prototype $\mathrm{J} 670 / 71$ and prime G-2/74, were passaged in $\mathrm{HEK}_{3}, \mathrm{MK}_{3}$ and $\mathrm{HeLa}_{7}$, and in $\mathrm{MK}_{3}$ and $\mathrm{HeLa}_{7}$, respectively. They were plaque purified three times, and then propagated once in HeLa cells in maintenance medium without bovine plasma albumin (Fraction V, Armour). The cultures, which showed cytopathic effect after virus inoculation, were freeze- and -thawed three times. The supernatants of culture fluids were divided into 2-ml portions and stored at $-20 \mathrm{C}$ as virus stock.

Sera: Two kinds of rabbit hyperimmune serum prepared with two EV70 strains, J 670/71 and G-2/74, by the procedure already described (Kawamoto, 1976, 1979), were used for the neutralization test (NT) and kinetic-NT.

Cell cultures and media: HeLa cells, kindly offered by Dr. H. Matsumiya (Hokkaido University School of Medicine, Sapporo), were used in this part. The cells were propagated in Roux bottles to multiplicate virus stock, and the growth medium used here was original Dulbecco's YLE supplemented with $10 \%$ newborn calf serum and $0.075 \%$ bicarbonate.

Infectivity assay: The fractionated viruses as well as the original ones were titrated with the micro tissue culture (MTC) system and by the plaque technique described previously (Kawamoto, 1976, 1979).

Analysis of neutralization activity: Cross-NT and kinetic-NT accorded those described previously (Kawamoto, 1976, 1979).

Adsorption chromatography with hydroxyl apatite gel: Hydroxyl apatite 
gel (Nippon Chem. Co., Ltd.) was used instead of calcium phosphate gel. Chromatographic operation was the modified procedures previously described by Ozaki et al. (1965) and by Gaudin et al. (1971). The hydroxyl apatite gel was equilibrated with $0.005 \mathrm{M}$ phosphate buffer at neutral $\mathrm{pH}$ by decantation three times with the same buffer, and stored at $4 \mathrm{C}$ until chromatographic operation. Prior to chromatography, the gel was further washed with the same ionic strength buffer by centrifugation at $2,000 \mathrm{rpm}$ for $5 \mathrm{~min}$. The virus stock was diluted fourfold with $0.0005 \mathrm{~m}$ phosphate buffer at neutral $\mathrm{pH}$, and the dilution was mixed with gel precipitate prepared from an equal volume of gel suspension. Viruses were allowed to be adsorbed at $25 \mathrm{C}$ for $90 \mathrm{~min}$ by shaking at 25 oscillations/min. The supernatant was removed by centrifugation, and then the remaining gel was washed with $0.005 \mathrm{M}$ phosphate buffer at neutral $\mathrm{pH}$ of the same volume to eliminate non-adsorbed particles. The adsorbed particles were stepwisely eluted from the gel with the buffer at neutral $\mathrm{pH}$ of the same volume by increasing the ionic strength from $0.05 \mathrm{M}$ to $0.5 \mathrm{M}$. The eluted fractions were designated as free virus, including unadsorbed and washed viruses and the sequential fractions from $\mathrm{F} 1(0.05 \mathrm{M})$ to $\mathrm{F} 6(0.5 \mathrm{M})$ in the ascending order of high ionic strength. In preliminary tests, it was found that more than $90 \%$ of the input of each virus were adsorbed to the gel at a concentration of $20 \mathrm{mg} / \mathrm{ml}$ at $25 \mathrm{C}$ for $90 \mathrm{~min}$ by 25 oscillations/min.

Consequently, operation of chromatography was carried out with a 2-ml aliquot of the diluted virus stock under these conditions. Each fraction except $\mathrm{F} 1(0.05 \mathrm{M})$ and $\mathrm{F} 2(0.1 \mathrm{M})$ was appropriately diluted to be equilibrated to the ionic strength of $0.1 \mathrm{~m}$ buffer with sterile distilled water after passage through $0.22 \mu$ millipore filter, and then diluted twofold with a usual maintenance medium. Each of the treated fractions was stored at $-20 \mathrm{C}$ until analysis. A portion of untreated $\mathrm{F} 1(0.05 \mathrm{M})$ from two viruses was purified by re-chromatography in the same manner as mentioned above, and then eluted with the same ionic strength $(0.05 \mathrm{M})$ at neutral $\mathrm{pH}$.

\section{Results}

\section{Experiment 1. Numerical Analysis of Neutralization Activities of 12 Strains of $E V 70$}

The results of kinetic-NT are shown as principal data matrix $X$ in Table I. The correlation coefficients, calculated from possible combinations with six hyperimmune sera, are shown as correlation coefficient matrix $R$ in Table II. Antigenic determinant factors and their loadings, stepwisely calculated from matrix $R$, are shown as matrix $A$ in Table III. Matrix $A$ is composed of four different factors and their loadings were each under each variable, i.e. immune serum. The influences of different factors among six variables can be compared with individual factor contributions each of which is sum of factor loadings. The contribution by the primary factor showed a significantly higher value than any 
TABLE I

Normarized neutralization rate constants (NK values) for twelve EV 70 strains isolated the period from 1971 to 1976

\begin{tabular}{|c|c|c|c|c|c|c|}
\hline \multirow{3}{*}{$\mathrm{EV} 70$ isolates } & \multicolumn{6}{|c|}{ Rabbit immune serum against } \\
\hline & \multicolumn{2}{|c|}{$\mathrm{J} 670 / 71$} & \multirow{2}{*}{ HK $3454 / 71$} & \multirow{2}{*}{ G-10/72 } & \multirow{2}{*}{$\# 137 / 73$} & \multirow{2}{*}{$\mathrm{G}-2 / 74$} \\
\hline & $A^{\circ}$ & $\mathbf{B}$ & & & & \\
\hline $\mathrm{J} 670 / 71$ & 100 & 100 & 70 & 84 & 69 & 89 \\
\hline HK $3454 / 71$ & 98 & 71 & 100 & 100 & 63 & 92 \\
\hline Rabat $6 / 71$ & 100 & 73 & $\overline{73}$ & 94 & 76 & 91 \\
\hline$\# 99 / 72$ & 94 & 93 & 98 & 98 & 95 & 94 \\
\hline G-10/72 & 66 & 56 & 14 & 100 & 70 & 98 \\
\hline$\# 137 / 73$ & 80 & 65 & 72 & $\overline{91}$ & 100 & 94 \\
\hline$\# 141 / 74$ & 38 & 25 & 12 & 38 & $\overline{46}$ & 89 \\
\hline HP $23 / 74$ & 44 & 12 & 15 & 98 & 68 & 84 \\
\hline $\mathrm{G}-2 / 74$ & 50 & 44 & 13 & 74 & 41 & 100 \\
\hline J $150 / 75$ & 50 & 18 & 57 & 84 & 65 & 91 \\
\hline HP $83 / 75$ & 50 & 40 & 19 & 67 & 67 & 100 \\
\hline$G-6 / 76$ & 43 & 40 & 16 & 59 & 50 & 100 \\
\hline
\end{tabular}

* Each number expresses the average NK value of each serum-virus combination. The underline indicates the NK value for isologous serum-virus combination. (Referred to the data published by Kawamoto, 1979)

TABLE II

Correlation coefficient matrix $R$ calculated for possible combinations of six antisera from $N K$ values obtained by kinetic NT

\begin{tabular}{lcccccr}
\hline \multirow{2}{*}{ Antiserum } & \multicolumn{7}{c}{ Antiserum } \\
\cline { 2 - 7 } & J 670/71-A & J 670/71-B & HK 3454/71 & G-10/72 & $\# 137 / 73$ & G-2/74 \\
\hline J 670/71-A & - & 0.907 & 0.912 & 0.631 & 0.599 & -0.175 \\
J 670/71-B & 0.907 & - & 0.812 & 0.472 & 0.512 & 0.079 \\
HK 3454/71 & 0.912 & 0.812 & - & 0.510 & 0.660 & -0.179 \\
G-10/72 & 0.631 & 0.472 & 0.510 & - & 0.610 & 0.098 \\
\# 137/73 & 0.599 & 0.512 & 0.660 & 0.610 & - & -0.172 \\
G-2/74 & -0.175 & 0.079 & -0.179 & 0.098 & -0.172 & - \\
\hline
\end{tabular}

Numbers express correlation coefficients among serum combinations.

of the sequent ones. All of them, except anti-G-2/74 serum, were approximately equal among the primary factor loadings, whereas the contributions by sequent three different factors were gradually decreased after the secondary factor. In this connection, there were no significant differences among the antisera in individual factor loadings. Consequently, it was considered that the primary factor might be closely related to intratypic variability among 12 strains, whereas sequent others, i.e. the secondary factor as the representative, might be associated with common antigen. In other word, the former one was designated as variable 


\section{TABLE III}

Factor loading matrix $A$ of anti-EV 70 serum by factor analytics

\begin{tabular}{|c|c|c|c|c|c|}
\hline \multirow{2}{*}{ Antiserum } & \multicolumn{4}{|c|}{ Factor loading } & \multirow{2}{*}{ Communarity } \\
\hline & $A_{1}$ & $\mathbf{A}_{2}$ & $\mathrm{~A}_{3}$ & $\mathrm{~A}_{4}$ & \\
\hline J $670 / 71-A$ & 0.888 & 0.229 & 0.020 & -0.021 & 0.841 \\
\hline J $670 / 71-B$ & 0.860 & 0.195 & 0.159 & 0.070 & 0.808 \\
\hline HK $3454 / 71$ & 0.839 & 0.359 & 0.130 & 0.035 & 0.851 \\
\hline G-10/72 & 0.717 & 0.055 & -0.017 & 0.007 & 0.517 \\
\hline$\# 137 / 73$ & 0.683 & 0.027 & 0.180 & 0.113 & 0.512 \\
\hline G-2/74 & -0.108 & 0.272 & 0.080 & -0.007 & 0.092 \\
\hline Contribution & 3.879 & 1.137 & 0.552 & 0.197 & - \\
\hline
\end{tabular}

\section{TABLE IV}

Factor score against each antigenic determinant factor on $\mathrm{EV}$ 70 particle

\begin{tabular}{lrrrr}
\hline \multirow{2}{*}{ EV 70 isolates } & \multicolumn{4}{c}{ Factor score } \\
\cline { 2 - 5 } & VAF & CAF $_{1}$ & CAF $_{2}$ & CAF $_{3}$ \\
\hline J 670/71 & 1.65 & 0.48 & 0.28 & 0.14 \\
HK 3454/71 & 4.46 & 0.79 & 0.19 & 0.05 \\
Rabat 6/71 & 4.52 & 0.54 & 0.24 & 0.11 \\
$\#$ 99/72 & 1.64 & 0.97 & 0.67 & 0.33 \\
G-10/72 & -1.06 & 0.01 & -0.01 & 0.00 \\
$\# 137 / 73$ & 0.07 & 0.51 & 0.50 & 0.27 \\
\#141/74 & -1.74 & -1.03 & -0.54 & -0.28 \\
HP 23/74 & 0.06 & -1.02 & -0.53 & -0.09 \\
G-2/74 & -2.07 & -0.21 & -0.32 & -0.11 \\
J 150/75 & -0.95 & -0.32 & -0.23 & -0.08 \\
HP 83/75 & -2.45 & -0.16 & -0.04 & -0.07 \\
G-6/76 & -2.33 & -0.30 & -0.23 & -0.18 \\
\hline
\end{tabular}

VAF, variable antigenic factor; CAF, common antigenic factor.

antigenic factor (VAF), while the latter three were designated as common antigenic factor (CAF). As shown in Table III, an individual communality, expressed as sum of squares of factor loadings under each variable, was used as embodying parameter to elucidate the antibody makeups of VAF and CAF in varying proportions. Consequently, it was considered that anti-G-2/74 serum, which was different from other five antisera, might be composed of proportional makeup with CAF rather than VAF. As shown in Table IV, 12 strains were compared from one to another with respect to CAF and VAF scores as numerical measure of antibody makeup. HK $3454 / 71$ and Rabat $6 / 71$ were similar each other with respect to VAF and CAF scores, and, especially, their VAF makeups were significantly higher than those of other Japanese isolates.

Therefore, it became clear that they could be differentiated from Japanese 
strains with respect to the VAF makeup. In contrast, it was found that VAF scores had successively drifted from prototype-like virus to prime-like one along VAF axis. CAF scores, on the contrary, were scarcely changeable after 1971, because there were no significant differences in CAF scores among 12 strains.

\section{Experiment 2. Chromatographic Analysis of Intratypic Variabilities of EV70}

Elution behaviors of input viruses: The J670/71 and the G-2/74 viruses, adsorbed onto hydroxyl apatite gel, were stepwisely fractionated with phosphate buffer at neutral $\mathrm{pH}$ by increasing ionic strength. As shown in Table V, the virus inputs of $\mathrm{J} 670 / 71$ and $\mathrm{G}-2 / 74$ were adsorbed in $90 \%$ and $91 \%$, respectively. There was no significant difference in the adsorption rate between two strains. In comparison of the infectivities of the eluted fractions, $46.8 \%$ and $21.7 \%$ of virus inputs of $\mathrm{J} 670 / 71$ and G-2/74 were recovered in F1 $(0.05 \mathrm{M})$, while $21.5 \%$ and $46.5 \%$ of them were recovered in F2 $(0.1 \mathrm{M})$, respectively. A large amount of adsorbed viruses were thus recovered in low ionic strength buffer. However, less than 3 to $4 \%$ of virus inputs were still eluted in sequent fractions of high ionic strength, F3 $(0.2 \mathrm{M})$ through $\mathrm{F} 6(0.5 \mathrm{M})$. In the elution pattern, the recovery peak of $\mathrm{J} 670 / 71$ appeared at lower ionic strength than did G-2/74, but there was no significant difference in the elution behavior at high ionic concentrations between two intratypic viruses.

Cross-NT of fractionated viruses with rabbit sera: Neutralization of the fractionated viruses as well as the original ones was analyzed by cross-NT with two rabbit immune sera. As shown in Table VI, F1 $(0.05 \mathrm{M})$ and F2 $(0.1 \mathrm{M})$ of J 670/71 against homologous antiserum showed fourfold higher virus-neutralizing (VN) titers than those against heterologous antiserum. Accordingly, it was

\section{TABLE V}

Recovery of prototype and primetype EV 70 strains from hydroxyl apatite chromatography

\begin{tabular}{|c|c|c|c|c|}
\hline \multirow{2}{*}{ Fraction } & \multicolumn{2}{|c|}{ Prototype J 670/71 } & \multicolumn{2}{|c|}{ Primetype G-2/74 } \\
\hline & $\mathrm{TCID}_{50} / 25 \mu 1 \mathrm{R}$ & ecovery $(\%)$ & $\mathrm{TCID}_{50} / 25 \mu 1$ & Recovery (\%) \\
\hline Original virus fluid & $1.0 \times 10^{6}$ & & $2.2 \times 10^{5}$ & \\
\hline Free virus after adsorption & $1.0 \times 10^{5}$ & - & $2.0 \times 10^{4}$ & - \\
\hline F $1(0.05 \mathrm{M})^{\mathrm{a}}$ & $4.7 \times 10^{5}$ & $(46.8)$ & $4.7 \times 10^{4}$ & $(21.7)$ \\
\hline $\mathrm{F} 2(0.1 \mathrm{M})$ & $2.2 \times 10^{5}$ & $(21.5)$ & $1.0 \times 10^{5}$ & $(46.5)$ \\
\hline F $3(0.2 \mathrm{M})$ & $3.2 \times 10^{4}$ & $(3.2)$ & $1.0 \times 10^{4}$ & $(4.7)$ \\
\hline F $4(0.3 \mathrm{M})$ & $4.7 \times 10^{3}$ & $(0.5)$ & $4.7 \times 10^{2}$ & $(0.2)$ \\
\hline F $5(0.4 \mathrm{M})$ & $3.2 \times 10^{3}$ & $(0.3)$ & $4.7 \times 10^{2}$ & $(0.2)$ \\
\hline F $6(0.5 \mathrm{M})$ & $3.2 \times 10^{3}$ & $(0.3)$ & $4.7 \times 10^{2}$ & $(0.2)$ \\
\hline
\end{tabular}

Note: a, F $1(0.05 \mathrm{M})$ is the first fraction eluted with $0.05 \mathrm{M}$ phosphate buffer at neutral $\mathrm{pH}$. 
TABLE VI

Cross neutralization with rabbit immune sera against original viruses and their chromatographic fractions

\begin{tabular}{|c|c|c|c|c|c|c|}
\hline \multirow{2}{*}{ Fraction } & \multirow{2}{*}{$\begin{array}{c}\text { Challenge } \\
\text { of }\end{array}$} & \multicolumn{2}{|c|}{ Antiserum against } & \multirow{2}{*}{$\begin{array}{c}\text { Challenge } \\
\text { of } \\
\text { G-2 origin } \\
\mathrm{TCID}_{50} / 25 \mu \mathrm{l}\end{array}$} & \multicolumn{2}{|c|}{ Antiserum against } \\
\hline & & $\mathrm{J} 670 / 71$ & $\mathrm{G}-2 / 74$ & & $\mathrm{~J} 670 / 71$ & $\mathrm{G}-2 / 74$ \\
\hline Original virus fluid & 100 & $2048^{a}$ & 256 & 200 & 1024 & $1024^{b}$ \\
\hline F $1(0.05 \mathrm{M})$ & 47 & 2048 & 512 & 316 & 512 & 512 \\
\hline F $2(0.1 \mathrm{M})$ & 47 & 2048 & 512 & 47 & 1024 & 2048 \\
\hline F $3(0.2 \mathrm{M})$ & 47 & 2048 & 1024 & 47 & 1024 & 2048 \\
\hline $\mathrm{F} 4(0.3 \mathrm{M})$ & 47 & 512 & 512 & 100 & 512 & 512 \\
\hline F $5(0.4 \mathrm{M})$ & 47 & 512 & 512 & 47 & 512 & 512 \\
\hline
\end{tabular}

Note: $a$ and $b$, homologous $50 \%$ virus neutralizing (VN) titers as reciprocals of serum dilution step.

possible that $\mathrm{F} 1(0.05 \mathrm{M})$ of two strains proportionally composed of more variant particles than intratypic common particles of EV70, while the sequent fractions after F3 $(0.2 \mathrm{M})$ predominantly involved common particles. It was considered that antigenic makeups of virus inputs were segregated into two intratypic antigenic groups with respect to the elution behavior in low and high ionic strength at neutral $\mathrm{pH}$, respectively.

Kinetic-NT of re-chromatographic fractions with rabbit immune sera: Neutralization of re-chromatographic F1 $(0.05 \mathrm{M})$ fractions of two viruses was analyzed by kinetic-NT with rabbit hyperimmune sera. As shown in Table VII, J 670/71 showed no significant differences in NK value between re-fractionated F1 $(0.05 \mathrm{M})$ and its original virus against two antisera, while G-2/74 showed highly significant differences $(\mathrm{p}<0.01)$ in $\mathrm{NK}$ value by the chai square test between refractionated F1 $(0.05 \mathrm{M})$ and its original virus against two antisera. As the results, with anti-J 670/71 serum, re-fractionated Fl of G-2/74 showed a lower NK value than did its original virus. Consequently, it was concluded that the virus populations of two strains were heterogenic in the proportion of variable virus particle to common ones.

TABLE VII

$N K$ values of kinetic neutralization of original viruses and their re-chromatographic fraction, $F 1(0.05 \mathrm{M})$, with rabbit immune sera

\begin{tabular}{clcc}
\hline \multirow{2}{*}{ Virus } & \multicolumn{1}{c}{ Fraction } & \multicolumn{2}{c}{ Antiserum against } \\
\cline { 2 - 4 } & & $\mathrm{J} 670 / 71$ & $\mathrm{G}-2 / 74$ \\
\hline J 670/71 & Original virus fluid & $\underline{100}$ & 89 \\
& Re-fractionated F 1 $(0.05 \mathrm{M})$ & 100 & 102 \\
$\mathrm{G}-2 / 74$ & Original virus fluid & 50 & 100 \\
& Re-fractionated F 1 (0.05 M) & 28 & 100 \\
\hline
\end{tabular}

The underline indicates NK value for isologous serum-virus combination. 


\section{Discussion}

From factor analysis in experiment 1, it was considered that two antigenic determinant sites in varying proportions, i.e. VAF and CAF, might exist as the antigen makeup of EV70, and VAF might be closely associated with intratypic antigenic drift. Furthermore, the drift could be explained by the alteration hypothesis in variation of factor scores given to 12 strains.

It was suggested that factor analytics applied here was useful as an embodying technique for quantitative estimation in virological studies. A similar concept was recently reported by others.

Iwasaki et al. (1976, 1977) attempted numerical classification of A/Hong Kong influenza virus current strains using average distant coefficience obtained by cross-hemagglutination inhibition (HI) tests.

They considered that viral $\mathrm{HA}$ antigens might be composed of various antigenic determinant sites, and intratypic variation among type A influenza viruses might depend upon the proportion of $\mathrm{HA}$ antigenic sites. We proposed in the present study that EV70 might be a virus type with heterogeneity, and the drift might have occurred by its heterogeneity. Such heterogeneity has been investigated by chromatographic analysis in many viruses, i.e. in polioviruses with diethylaminoethyl-cellulose columns (Hodes, Zepp and Ainbender, 1960), with $\mathrm{Al}(\mathrm{OH})_{3}$ gel (Woods and Robbins, 1961) and with calcium phosphate gel (Ozaki et al., 1965), and in echovirus type 11 with calcium phosphate gel (Gaudin et al., 1971). In the present chromatographic analysis, intratypic variabilities of EV70 specifically showed in low ionic strength at neutral $\mathrm{pH}$, and the segregated virus populations were shown to be stable in various ionic strength solutions. It was demonstrated that EV70 was composed of four different structural proteins like polioviruses (Esposito and Obijeski, 1976). Recently, it was noted that several group A coxsackieviruses (e.g. A-13, 15, 18, and 21) were rapidly inactivated in low ionic strength concentration at neutral $\mathrm{pH}$, and the phenomenon was due to inhibiting adsorption onto susceptible cells by specific structural alteration in the coxsackievirus capsid induced under conditions of low ionic strength (Cords, James and McLaren, 1975).

However, we considered that antigenic alteration of EV70 presented here was quite different from that of several group A coxsackieviruses mentioned above.

In conclusion, it was confirmed that original virus populations of two intratypic strains used here were heterogeneous as proportional mixtures composed of neutralization-sensitive and -insensitive particles, and the former ones were equilibrated in high ionic strength concentration and the latter ones in low ionic strength concentration at neutral $\mathrm{pH}$, respectively. Therefore, it was considered that neutralization-insensitive particles of EV70 might become the predominant population as a result of the sequent antigenic drift. 


\section{Acknowledgements}

I wish to thank Dr. H. Matsumiya, School of Medicine, Hokkaido University, and Dr. F. Yamada, Director of this institute, for their constant interests and helpful suggestions during the course of this study, Dr. K. Miyamura, Central Virus Diagnostic Laboratory, National Institute of Health, for her practical advice on chromatographic segregation of virus populations, and Dr. S. Katsuno, Department of Hygiene, Hyogo College of Medicine, for his earnest discussions on factor analytics.

\section{REFERENCES}

Abraham, A. (1967): Isolation of two enteroviruses, possible "prime" strains of coxsackie A type 17 virus. Proc. Soc. Exptl. Biol. Med., 125, 195-200.

Choppin, P. W. ANd EgGers, H. J. (1962): Heterogeneity of coxsackie B4 virus: two kinds of particles which differ in antibody sensitivity, growth rate, and plaque size. Virology, 187, $470-476$.

Cords, C. E., James, C. G. And McLaren, L. C. (1975): Alteration of capsid proteins of coxsackievirus A 13 by low ionic concentrations. J. Virol., 15, 244-252.

DömöK, I. AND Simon, M. (1966): Intratypic variability of ECHO virus type 19. Virology, 29, $553-569$.

Esposito, J. J. ANd ObiJeski, J. F. (1976): Enterovirus type 70 virion and intracellular proteins. J. Virol., 18, 1160-1162.

Gaudin, O. G., Jeddi, M., VIAC, J. AND Sohier, R. (1971): Heterogenous viral population chromatography of ECHO virus type 11 on distinction of several fractions by calcium phosphate and kinetic neutralization test. Arch. ges. Virusforsch., 34, 14-22.

Harman, H. H. (1967): Modern factor analysis (2nd ed.). Univ. Chicago Press. Chicago, Ill.

Hodes, H. L., ZePp, H. H. ANd Ainbender, E. A. (1960): A physical property as a virus maker. Difference in avidity of cellulose resin for virulent (Mahoney) and attenuated (LSc, 2ab) strain of type 1 poliovirus. Virology, 11, 306-308.

IshiI, K., Nakazono, N. And SawaAd, H. (1977): Acute hemorrhagic conjunctivitis. Shōni Igaku, 10, 345-385 (in Japanese).

IWASAKI, K., ITo, T. AND Yoshida, Y. (1976): On the epidemic of type A influenza virus $\left(\mathrm{H}_{3} \mathrm{~N}_{2}\right)$ in Tokyo, -epidemiological survey and antigenic analysis of prevailing strains-. Japan. Med. J., No. 2709, 43-47 (in Japanese).

IwASAKI, K. (1977): Numerical classification of A/Hong Kong influenzavirus strains made on the basis of cross HI test. Ann. Rep. Tokyo Metr. Res. Lab., P. H., 28-1, 35-39 (in Japanese).

KAwAmoto, H. (1976): Virological and serological studies of acute hemorrhagic conjunctivitis (enterovirus type 70)-the antigenic analysis and serological epidemiology. Rinshō to Virus (Clin. Virol.), 4, 191-197 (in Japanese).

Kawamoto, H. (1979): Antigenic analysis of acute hemorrhagic conjunctivitis virus (enterovirus type 70). Microbiol. Immunol., 23, 859-866.

KozA, J. (1963): Calcium phosphate adsorption patterns of virulent and avirulent strains of poliovirus. Virology, 21, 477-481.

Margalith, M., Margalith, E. R., Rannon, L., Goldblum, T., Leventonkriss, S. and Goldblum, N. (1967): Segregation of mouse virulent and avirulent ECHO virus type 9 strains and correlation of mouse virulent with the "temperature" Rac/40 maker. Arch. ges. Virusforsch., $21,403-412$.

McBride, W. D. (1959): Antigenic analysis of polioviruses by kinetic studies of serum neutralization. Virology, 7, 45-58.

Nakamura, M., Yoshimoto, S., Asano, Y., Katsuno, S. And Sakamoto, K. (1978): An epidemiological study of anemia of farmer's wives in a rural area of Hyogo prefecture (part 1). Japan. J. Publ. Hlth, 25, 119-126 (in Japanese).

Ozaki, Y., Diwan, A. R., Takizawa, M. AND Melnick, J. L. (1965): Chromatography of poliovirus on calcium phosphate and its application to the identification of vaccine progeny strains. J. Bacteriol., 89, 603-610.

ShibA, S. (1976): Factor analysis method (3rd ed.). Univ. Tokyo Press, Tokyo (in Japanese). 
Simon, M. AND Dömök, I. (1963): Studies on intratypic variations of ECHO viruses. 1. Separation of hemagglutining and non hemagglutining virus particles from ECHO virus type 6 . Acta Microbiol. Acad. Sci. Hung., 10, 293-306.

Woods, W. A. And Robbins, F. C. (1961): The elution properties of type 1 polioviruses from $\mathrm{Al}(\mathrm{OH})_{3}$ gel. A possible genetic attribute. Proc. Nat. Acad. Sci., 47, 1501-1507. 